\title{
A noção de equivalência e a sua especificidade na tradução especializada
}

\author{
Maria Emília Pereira Chanut*
}

\begin{abstract}
We propose in our study a reflection on "functional equivalence" based on a comparative/ terminological bilingual (Portuguese from Brazil/ French from France) approach of specialized texts (certified) due to difficulties that are aggravated by particularities from Switzerland French. A presentation of the equivalence notion in translation theories is necessary to introduce the central issue of this article, namely, to show that "the functional equivalence" seems, in the case of the specialized translation, most appropriate. This happen because legal terms and/ or legal gifts in official documents are, in its essence, culturally marked, presenting a direction or different use, even though improper in countries that speak the same language, such as France and Switzerland.
\end{abstract}

Keywords: functional equivalence; specialized translation; cultural content; French from France; Switzerland French; Portuguese from Brazil.

Resumo: Este estudo, partindo de uma abordagem comparativa/terminológica bilíngue (português do Brasil/francês da França) de textos especializados (juramentados), cujas dificuldades são agravadas por particularidades do francês da Suíça, propõe uma reflexão sobre a "equivalência funcional". Uma apresentação das teorias referentes à noção de equivalência em tradução nos serve para introduzir a ideia central deste artigo, a saber, mostrar que a equivalência "funcional" é, no caso da tradução especializada, a mais apropriada, uma vez que os termos legais e/ ou jurídicos presentes nos documentos oficiais são, em sua essência, culturalmente marcados, podendo apresentar sentido ou uso diferente e até mesmo equivocado em países que falam a mesma língua, tais como a França e a Suíça.

Palavras-chave: equivalência funcional; tradução especializada; conteúdo cultural; francês da França; francês da Suíça; português do Brasil.

\footnotetext{
* Professora assistente doutora, Disciplina Língua francesa, no IBILCE-Unesp - São J osé do Rio Preto. Email: chanut@ibilce.unesp.br.
} 
Chanut, M. E. P. - A noção de equivalência e a sua especificidade na tradução especializada

\section{Introdução}

Em um estudo desenvolvido no âmbito de pesquisas sobre o francês da Suíça relacionado aos particularismos lexicais empregados na linguagem administrativa oficial, foi enfatizada a questão da "equivalência funcional" na tradução juramentada de documentos civis e escolares. 0 estudo abordou as diferenças socioculturais entre a França e a Suíça a partir dos termos relevantes nos domínios citados, retirados de um corpus de traduções juramentadas. Uma lista não exaustiva de termos foi apresentada como ilustração da problemática, com ênfase nos particularismos suíços, os chamados statalismes, encontrados a partir do "francês padrão" da França. Parte dos resultados desse estudo foi recentemente divulgada no Colóquio Traduction, terminologie, rédaction technique: des ponts entre le français et le portugais, realizado na Maison de I'Europe, Université Sorbonne Nouvelle Paris 3, nos dias 13-14 de janeiro de $2011^{1}$.

A partir dos particularismos encontrados, o estudo desenvolveu paralelamente uma reflexão sobre a noção de "equivalência funcional". A pesquisa nos confirmou o que a prática da tradução juramentada nos sugeria, ou seja, que nesse tipo de tradução, o tradutor, além de possuir profundo conhecimento nas duas línguas em questão e alguma familiaridade com a linguagem cartorária e jurídica, deve buscar concretamente em ambas as línguas os termos suficientemente semelhantes e explícitos em sua "equivalência funcional", a fim de garantir a compreensão e a comunicação e, principalmente, a confiabilidade. Em outras palavras, o tradutor deve buscar o termo que é admissível e assimilável a título funcional, uma vez que se trata de cumprir um ato de comunicação pertinente e eficaz na cultura de recepção.

\footnotetext{
${ }^{1}$ Todas as citações neste artigo cujas referências estão em língua francesa foram traduzidas pelo autor do artigo.
} 
Chanut, M. E. P. - A noção de equivalência e a sua especificidade na tradução especializada

Pretende-se, no caso específico deste artigo, divulgar, primeiramente, algumas considerações teóricas em torno da noção de "equivalência", uma vez que a mesma vem sendo historicamente utilizada por vários autores de formas diferentes e em disciplinas distintas. Em seguida, será abordada a questão da equivalência no texto de especialidade.

\section{A equivalência e as teorias da tradução}

0 "grau de equivalência" do texto de chegada com relação ao texto de partida foi, durante muito tempo, o objeto de controvérsias, principalmente no curso dos anos 1970, embora mesmo antes disso alguns estudiosos já tivessem tentado sistematizar tipologias, como por exemplo, Vinay e DARBELnet (1958), que se debruçaram sobre sete métodos de tradução, considerados hoje como uma taxonomia clássica das variações em tradução.

Até então, a tradução era percebida ou como uma atividade literária, ou como um fenômeno não literário. Só havia, na prática, dois modos de pesquisa: o primeiro se voltava para os problemas literários e rejeitava todo postulado teórico, toda norma e todo jargão da linguística, ao passo que 0 segundo se interessava por questões linguísticas e pretendia seguir um procedimento científico. Durante os anos 1970, como indica EdWIN GeNTZLER em sua obra Contemporary Translation Theories (1993), o procedimento adotado nas pesquisas de tradução sofreu uma transformação: em lugar de tentar resolver os problemas filosóficos se apoiando na natureza do sentido, a tradutologia passou a se preocupar mais com o modo como o sentido se desloca, tornando-se assim uma disciplina caracterizada por uma abertura ao trabalho interdisciplinar. Também, os especialistas da literatura começaram a trabalhar em projetos conjuntos com lógicos, linguistas e filósofos. Por outro lado, termos como correto, incorreto, literal, livre etc. passaram a diminuir 
Chanut, M. E. P. - A noção de equivalência e a sua especificidade na tradução especializada

em importância. Notou-se, portanto, uma mudança de tom nas teses e nas propostas apresentadas pelos diferentes teóricos. Ainda de acordo com Gentzler, essa mudança de orientação dos estudos e das pesquisas no domínio da tradução é atribuída, entre outros, principalmente a James Holmes², a quem devemos o termo Translations Studies - tradutologia em português - e a André Lefevere $^{3}$. Os trabalhos de Holmes e Lefevere estão na base da teoria da equivalência tal como a conhecemos e a aplicamos hoje. Igualmente importantes são os trabalhos de J OHN CATFORD (2000) e de GIDEON TOURY (1995).

Embora este estudo não tenha o objetivo de abordar extensamente as mais variadas teorias da tradução que, desde os anos 1950 (Vinay, Darbelnet, Catford e outros), buscam determinar as diferentes tipologias textuais, julgase fundamental para este trabalho traçar uma breve retrospectiva em torno da noção geral de "equivalência". Lembremos que a equivalência é um conceito pertencente ao domínio da tradutologia. A linguística contrastiva utiliza o conceito de correspondência, sendo que este designa um fenômeno diferente da equivalência.

Segundo VLADIMIR IVIR (1981), "a correspondência formal é um termo usado em análise contrastiva enquanto equivalência tradutória pertence à metalinguagem da tradução" (apud RodRIGUES, 2000, p. 19). Este autor explica que as duas áreas de estudo, a linguística contrastiva e a tradução, passam, especialmente nos anos 1960 e 1970, a discutir sobre a equivalência, mas que, na prática, estudiosos das duas áreas julgam necessários ambos os termos.

\footnotetext{
${ }^{2}$ Poeta e tradutor americano que ensinou tradução na Université de Amsterdã e que escreveu muitas obras de tradutologia, como The Name and Nature of Translation Studies, in The Translation Studies Reader, editada por Lawrence Venuti, London, Routledge, 2000, pp. 172185.

${ }^{3}$ Foi professor do Departamento de línguas germânicas da University of Texas, em Austin, e professor honorário de Tradutologia na University of Warwik. Ele é o autor de muitos livros como Translation of Poetry: Seven Strategies and a Blue Print, Assen, Van Gorcum, 1975 e Translation, Rewriting \& the Manipulation of Literary Frame, London, Routledge, 1992, 176 p, coll. «Translation Studies».
} 
Chanut, M. E. P. - A noção de equivalência e a sua especificidade na tradução especializada

Embora não seja a proposta deste artigo, vale lembrar que a linguística contrastiva, cujo principal objetivo é analisar (comparar) duas línguas a fim de identificar suas diferenças gerais e específicas, tem como campo de aplicação a aprendizagem de uma segunda língua. Isso significa que ela se refere à língua enquanto sistema. A correspondência é um conceito utilizado na análise contrastiva para descrever as frases e as estruturas que correspondem na língua de partida e na língua de chegada. Quanto à equivalência, ela se refere, sobretudo, ao "grau" de equivalência em que uma palavra, uma frase, ou mesmo um texto da cultura de partida pode ser considerado na língua e na cultura receptora. A equivalência tem traços do discurso ou da palavra e depende da tradução.

Os teóricos que definem a tradução por meio do conceito de equivalência são numerosos. Mais especificamente no âmbito da linguística temos J OHN CUNNISON CATFORD (2000), que tenta defini-la como a substituição de materiais textuais de uma língua por materiais equivalentes em outra língua. Eugene Nida, por sua vez, propõe que "a tradução consiste em produzir na língua de chegada o equivalente natural mais próximo da mensagem da língua de partida, primeiramente quanto à significação, depois quanto ao estilo" (apud Mounin 1986: 278). Segundo RodRIGUes (2000: 142-144), Gideon Toury propõe um reexame do conceito de equivalência, fazendo uma distinção entre os dois usos da palavra "equivalência", o "teórico" e o "descritivo". Para Toury, cuja abordagem descritiva adere aos princípios das teorias funcionalistas, a tradução é percebida como um processo sociocultural ${ }^{4}$. TOURY (1995) propõe um procedimento para se determinar se a tradução, na relação com seu original, se orienta para a língua de partida dita "formal" - ou para a língua de chegada - dita "funcional".

\footnotetext{
${ }^{4}$ Conferir anotações a respeito da obra e do método da análise de Toury em: Edwin Gentzler, Contemporary Translation Theory, Routledge, 1993, pp. 121-134.
} 
Chanut, M. E. P. - A noção de equivalência e a sua especificidade na tradução especializada

Anthony Pym (1992), teórico da tradução, ressalta que a equivalência é uma criação necessária para estabelecer uma comunicação intercultural. A dimensão cultural da comunicação constitui o eixo central da abordagem deste autor.

A origem da noção de equivalência é difícil de determinar, tanto que, como sabemos, Jakobson já utilizava esse termo em $1959^{5}$. Certos teóricos afirmam que o termo entrou no domínio da tradutologia depois de ter aparecido nos estudos de matemáticos. Esta hipótese poderia ser justificada pelo fato de que, nesse domínio, o termo equivalência designa uma relação simétrica entre os dados que poderiam ser substituídos um pelo outro sem provocar diferenças significativas. É inegável que o termo equivalência subentenda uma relação de valor igual, o que justifica seu emprego nos estudos matemáticos. Convém, todavia, analisar as diferenças do uso desse termo na linguística e na tradutologia.

A noção de equivalência é, de qualquer forma, partilhada pelos linguistas e teóricos da tradução. Os linguistas a associam à língua enquanto sistema e estudam suas diferentes estruturas e funções. Quanto aos teóricos da tradução, eles põem a equivalência no plano do discurso e a percebem como fruto da interação entre o tradutor e seu texto. Desse modo, a operação tradutória é considerada como um processo dinâmico de produção e não como um simples processo de substituição de estruturas ou de unidades preexistentes em uma língua por aquelas de outra língua. A equivalência ideal seria, portanto, aquela que, em uma situação de assimetria, permitiria ao texto de chegada funcionar ou ter uma utilidade, uma finalidade prática na cultura receptora da tradução.

Os primeiros debates sobre o tema da equivalência no domínio da tradutologia procuravam compreender o que devia ser equivalente: as

\footnotetext{
${ }^{5}$ J akobson (2000) supõe que não há equivalência completa entre as diferentes línguas e que mesmo os sinônimos de um mesmo código não são sinônimos perfeitos ou completos.
} 
Chanut, M. E. P. - A noção de equivalência e a sua especificidade na tradução especializada

palavras, as frases, as partes do texto, ou o texto inteiro. Até os anos 1970, 0 texto era percebido como uma sequência linear de unidade e a tradução como uma operação de decodificação, ao decorrer da qual o tradutor mudava as unidades do texto de partida pelas unidades equivalentes na língua de chegada. Hoje, a noção de "unidade equivalente" pode, segundo os diferentes teóricos, referir-se a uma palavra ou a um texto no seu conjunto. As teorias postas em evidência durante os anos 1970 abriram caminho para novas maneiras de abordar os problemas de tradução.

As teorias funcionalistas revolucionaram a tradutologia, analisando a tradução como um processo de comunicação pragmática na qual os textos de partida ou de chegada podem ter "funções" ou finalidades diferentes. Holmes (2000) considera a tradução, enquanto processo, como uma sequência de decisões que o tradutor toma para chegar ao seu destino e crê que essas decisões abrem algumas portas e fecham outras. Assim, o tradutor, mediador da comunicação interlinguística e intercultural, deve procurar uma equivalência que torne o texto de chegada "funcional" na cultura receptora. 0 tradutor não ignora, em sua prática, que a língua lhe impõe armadilhas quando lida com equivalências formais ou literais, ou seja, quando lida com termos que aparentemente podem ser traduzidos literalmente, pois são lexicalizados na língua de chegada.

É importante notar que o sentido do termo equivalência toma aqui uma nova dimensão. Quando utilizado em tradução, esse termo se remete a uma situação ou a um elemento equivalente no plano do discurso e não no plano do sistema da língua.

A tradução literária é a fonte à qual têm recorrido outros domínios da tradução, e isso compreende a tradução jurídica. A tradução especializada herdou os debates sobre a equivalência, os quais tomaram novas dimensões segundo os diferentes domínios de especialidade. 
Chanut, M. E. P. - A noção de equivalência e a sua especificidade na tradução especializada

A noção de equivalência - quando tratamos do texto de especialidade e, mais especificamente, de textos jurídicos ou aqueles submetidos à tradução juramentada - adquire uma significação bem particular, na medida em que os aspectos culturais e as diversidades sociopolíticas dos sistemas jurídicos determinam o uso dos termos em documentos oficiais, como veremos mais adiante.

\section{A importância do interesse pelas variedades geográficas}

A ferramenta básica e fundamental no trabalho de busca das equivalências em tradução especializada é o dicionário bilíngue. Além do desconhecimento das diferenças culturais entre duas línguas diferentes, como o português e o francês, acrescentado a seus sistemas jurídicos e administrativos diferentes, um desconhecimento das variedades geográficas (no caso desta pesquisa, o francês da Suíça, e suas diferenças socioculturais em relação ao francês da França) pode agravar a situação.

Os particularismos próprios ao francês empregado fora da França foram, em geral, negligenciados pelos autores de dicionários ao longo dos anos, como comprova a história da lexicografia francesa. 0 francês da Suíça, assim como o da Bélgica e do Quebec eram, até o final dos anos 1970, considerados e descritos como uma variedade regional do "francês padrão", ou francês de referência. A partir dos anos 1980, sobretudo, a situação mudou e uma valorização crescente começou a ser percebida principalmente pela presença das diferentes variedades do francês, presentes nas obras lexicográficas e na produção terminológica e, além disso, pelo reconhecimento da importância da variação lexical geográfica dos organismos 
Chanut, M. E. P. - A noção de equivalência e a sua especificidade na tradução especializada

internacionais de normalização. Surge no meio francófono uma nova disposição no sentido de preservar as identidades culturais nacionais e ao mesmo tempo encorajar a comunicação internacional. 0 francês da Bélgica, assim como o do Québec e da Suíça passam então a ser definidos como variedades nacionais e as designações de suas particularidades lexicais são chamadas, respectivamente, de belgicismos, quebecismos, e helvetismos (Hausmann 1986: 4-5, apud Galarneau; Vézina 2004: 6) ${ }^{6}$.

Atualmente, cresce, portanto, a tendência da abordagem dita "variacionista" ${ }^{7}$ em obras de vocabulários especializados, de léxicos e de bancos de dados terminológicos, com o objetivo de atender as necessidades de intercomunicação entre os francófonos, principalmente quando se trata de um uso oficializado de termos culturalmente marcados, como é o caso do léxico jurídico e/ ou administrativo.

Os termos oficiais do francês da França e do francês da Suíça muitas vezes são diferentes ou têm um uso diferente e um tradutor juramentado deve conhecer essas realidades, que normalmente não estão informadas nas obras lexicográficas disponíveis.

Quanto à noção de français de référence, vale informar que está atualmente bem estabelecida; esta foi assunto de um importante colóquio em Louvain-la-Neuve (Bélgica), em novembro de 1999, cujos Anais (Actes) constam nos Cahiers de I'Institut de linguistique de Louvain, vol. 26 et 27, 2000 e 2001 (edição de Michel FrancARD com a colaboração de GeneVIÈVE GERON e RÉGINE WILMET) ${ }^{8}$.

\footnotetext{
${ }^{6}$ Disponível em:

«ttp:// www. oqlf.gouv.qc.ca/ ressources/ bibliotheque/ officialisation/ reflexion topolectale 20080425. pdf >. Acesso em: 20/07/2010.

${ }^{7}$ FAULSTICH, ENILDE. Aspectos de terminologia geral e terminologia variacionista. In TradTerm, 7, p. 11-40, 2001.

8 Disponível em: বhttp:// www.bdlp.org/bdlp.pdf $>$, nota n. 23. Acesso em: 21/07/2010. Trata-se de um documento de apresentação da BDLP (Base de Données Lexicographiques Panfrancophone), organizado pelo Trésor des vocabulaires français - Réseau «Étude du français en francophonie»-AUF.
} 
Chanut, M. E. P. - A noção de equivalência e a sua especificidade na tradução especializada

Há um grande número de denominações empregadas para designar a variedade central à qual nos referimos para determinar os traços característicos de uma variedade geográfica do francês e, sem dúvida, a mais conhecida é o français standard (francês padrão). Porém, essa denominação tem a desvantagem de evocar uma dimensão normativa em contextos onde esse aspecto não deveria ser levado em conta. Assim, passou-se a dar preferência à denominação de "francês de referência", por ser mais neutra e não ser ambígua. São considerados como pertencentes a esse francês todos os empregos repertoriados nos dicionários e outras fontes (por exemplo, as gramáticas) que descrevem essa variedade "de prestígio" levada em conta pelos lexicógrafos da França. "Francês de referência" tem a vantagem de expressar claramente a ideia de que a variedade assim designada é tomada em posição de comparação. O francês dos dicionários da França é a única variedade conhecida por toda a francofonia; é a ele que se referem todos os professores de francês do mundo inteiro. É então por comparação com esse francês que será determinado se um emprego lexical é uma particularidade, ou variedade geográfica. Este método diferencial possibilita-nos evidenciar 0 que é comum ou o que é particular à variedade do francês estudada.

Esta pesquisa, ao incluir os particularismos da variedade suíça no repertório com vistas a um futuro glossário, considerou que, no caso da tradução especializada, o fator cultural que diferencia os usos em função da variação geográfica compõe um conjunto lexical específico e considerado como uma língua à parte.

Porém, ao buscar as equivalências terminológicas em outra língua, é preciso ter consciência de que "uma mesma realidade extralinguística pode ser analisada de pontos de vista muito divergentes em línguas diferentes, a partir dos laços profundos e complexos que existem entre estrutura da língua e visão de mundo" (Alpízar-CASTILlo 1997: 102). Por essa razão, para um termo na língua $A$ não haverá necessariamente um termo equivalente na língua $B$. Ainda segundo AlpízAR-CASTILLO (1997: 101), "a correspondência entre termos 
Chanut, M. E. P. - A noção de equivalência e a sua especificidade na tradução especializada

de línguas diferentes situa-se em um diapasão de possibilidades que vai do total recobrimento do conteúdo do termo da língua $A$ por um da língua $B$, até a total falta de equivalência, passando por uma variada gama de recobrimentos parciais".

\section{A equivalência no texto de especialidade}

No direito, a definição de um conceito pode a qualquer instante ser modificada no interior do mesmo sistema por meio da legislação ou da jurisprudência. Essa instabilidade intensifica uma dificuldade intrínseca a essa disciplina, originalmente escorada em noções fundamentais relativamente imprecisas. Em outras palavras, a nomenclatura do direito se distingue por sua característica incerta que provém, segundo GÉMAR (1995), do caráter impreciso de seus conceitos. Tomemos como exemplo o termo direito. GÉmAR (1979) verificou a definição dada por diferentes dicionários. Ele constatou que as definições variam de um dicionário para outro. No entanto, trata-se de um termo chave no domínio jurídico.

Além disso, em uma perspectiva comparatista, a situação se complica ainda mais. Na tradução jurídica, lida-se com mundos reais diferentes, ou seja, não se trata simplesmente de uma visão de mundo diferente em função da língua de quem o percebe, pois não é a percepção do mesmo referente que muda, é o próprio referente que é diferente. Estamos falando da confrontação de duas culturas jurídicas, cada uma com suas particularidades e seus termos específicos. Às vezes, existe um referente idêntico na outra cultura, em outros momentos, um referente comparável, mas com diferenças significativas e, muitas vezes, não existe nenhum referente comparável. Ou seja, não há "equivalente" linguístico, quando comparadas culturas jurídicas diferentes, nem nas que empregam a mesma língua. 
Chanut, M. E. P. - A noção de equivalência e a sua especificidade na tradução especializada

O teor textual da tradução juramentada possui, como todo texto especializado, uma finalidade comunicativa específica, uma forma discursiva determinada e uma terminologia exclusiva. Isso significa que, embora a mensagem seja transmitida por meio da língua escrita, no caso do texto especializado, a língua é um instrumento de comunicação, uma ferramenta na transmissão da mensagem. Como esclarece Antolne Berman (1991) "no caso do texto especializado, o que é transmitido é um conjunto delimitado de informações delimitadas relativas a um domínio ele próprio delimitado pertencente a este conjunto que denominamos as 'tecnologias'" (p. 11). Nesse texto, intitulado Traduction spécialisée et traduction littéraire ${ }^{9}$, Antoine Berman tem uma proposta estratégica: busca diferenciar os dois gêneros de tradução mostrando a necessidade de se conservar a essência do ensino da tradução literária ainda que encorajando o papel promotor da comunicação no ensino da tradução especializada. Em outras palavras, segundo ele, é por essa diferenciação, pela oposição mesmo dos dois gêneros de tradução que se torna possível "cumprir o destino tradicionalizante" na tradução de obras e o "destino comunicacional" na tradução especializada. Essa preocupação, voltada especialmente ao ensino da tradução nas universidades, serviu-nos aqui em outra direção. Tentamos redefinir, em consonância com esta diferenciação fundamental exposta por Berman, o que se costumou chamar de "equivalente" em tradução, e mais especificamente, de textos técnicos e especializados. Berman completa:

A transferência lingüística (sic) desse conjunto obedece a um conjunto de regras estratégicas determinadas: as informações devem ser transmitidas de modo claro, confiável e eficaz; sendo o texto de origem destinado a um público $X$ determinado, sua transferência lingüística (sic) deve adaptá-lo a um novo público $X$, ele próprio determinado; tendo o texto de origem uma estrutura discursiva

\footnotetext{
${ }^{9}$ Texto presente nas Atas do Colóquio Internacional organizado pela Associação Europeia de Linguístas e de Professores de Línguas (AELPL), realizado em 21 e 22 de março de 1991, na Escola Nacional Superior de Artes, em Paris. Editado por La Tilv, Paris, 1991, p. 157.
} 
Chanut, M. E. P. - A noção de equivalência e a sua especificidade na tradução especializada

determinada, até certo ponto, pela "gramática cultural" (Gouadec) de seu local de produção, sua tradução tem a obrigação de remanejar, até certo ponto, esta estrutura discursiva, de modo a adaptá-lo à "gramática cultural" de seu local de destino, a fim de ele seja stricto sensu receptível. (p. 11)

"Essas regras são absolutas", ele acrescenta, afirmando que tais regras determinam, por sua vez, metodologias precisas que garantem que a transferência de informação poderá se desenvolver de modo satisfatório.

As dificuldades da tradução jurídica são, todavia, maiores, porque comportam, além da passagem de uma língua para outra e de toda cultura onde está inserida, um componente a mais: trata-se da transposição da mensagem de um sistema de direito para um outro. Ou seja, além do contexto ligado ao documento original, um termo pode igualmente ser indissociável do contexto legal no qual ela intervém.

As dificuldades da equivalência lexical se manifestam não somente na tradução legislativa ou jurídica, mas também na tradução de documentos comuns de direito comercial, por exemplo, especialmente se estes envolvem empresas constituídas de acordo com o sistema de direito de países diferentes. Ainda de modo mais geral, as dificuldades de tradução dos termos com forte conteúdo cultural não se limitam somente ao campo da tradução jurídica propriamente dita, pois nem mesmo os documentos administrativos relativamente simples estão livres de tais termos. Dependendo do tipo de tradução solicitada, juramentada ou livre, o tradutor disporá de abordagens tradutivas mais ou menos livres. Lembremos que as normas que regem a profissão recomendam uma tradução juramentada "transparente e absolutamente literal", a ponto de ter de reproduzir até os eventuais erros do original ${ }^{10}$.

\footnotetext{
${ }^{10}$ Essas questões de fidelidade e literalidade são complexas e vale mencionar nesse sentido 0 precioso trabalho desenvolvido pelo Tradutor Juramentado e Professor de Linguística da FFLCH-USP, Francis Aubert, do qual destacamos o artigo "Tipologia da tradução: o caso da tradução juramentada" (1996), e os diversos artigos publicados na Ipsis Literis, uma revista
} 
Chanut, M. E. P. - A noção de equivalência e a sua especificidade na tradução especializada

Os tradutores, quando estão a serviço da justiça, têm geralmente 0 dever de traduzir "literalmente". Para os juízes em geral, e inclusive nas leis que prescrevem as normas da profissão, a tradução literal significa "tradução fiel". Mas, o que significa "traduzir literalmente"? A maioria dos dicionários define a tradução literal como aquela feita "palavra por palavra", ou seja, em conformidade exata com o texto original. 0 dicionário eletrônico Houaiss, por exemplo, define literal como: "que reproduz exatamente, palavra por palavra, determinado texto ou trecho de um texto". Felizmente, o antigo debate entre os defensores da tradução literal e os da tradução livre que dividiu os linguistas e os tradutólogos parece ter ficado no passado e hoje as noções de fidelidade e de literalidade na tradução foram substituídas por outras noções menos radicais, como os "graus ou níveis da equivalência" entre o original e sua tradução.

Muitos tipos de equivalências se cruzam, ou seja, elas recebem denominações diferentes segundo os teóricos, mas elas designam geralmente o mesmo conceito ou conceitos que apresentam uma ínfima diferença. Alguns teóricos, SNeLL-HoRnBy (1995), por exemplo, assumem ter identificado mais de 57 equivalências, entre outras, linguísticas, paradigmáticas, estilísticas, semânticas, formais, referenciais, pragmáticas, dinâmicas e, seguramente, a equivalência funcional. Esses são os tipos de equivalências mais frequentemente analisados, porém, é necessário perceber que esses equivalentes situam-se em planos diferentes. A equivalência linguística, por exemplo, situa-se no plano da semântica, a equivalência paradigmática situase no plano gramatical e a equivalência pragmática situa-se no plano extralinguístico.

VinAY e DARbeLnet (1958) foram os pioneiros na elaboração de uma tipologia de procedimentos comparando sistematicamente textos originais com suas traduções. Vinay e Darbelnet defendem que os diferentes métodos

da ATPIESP (Associação Profissional dos Tradutores Públicos e Intérpretes Comerciais do Estado de São Paulo). 
Chanut, M. E. P. - A noção de equivalência e a sua especificidade na tradução especializada

ou procedimentos poderiam ser resumidos em apenas sete, cuja utilização pode dar-se de maneira isolada ou combinada: o empréstimo, o decalque, a tradução literal, a transposição, a modulação, a equivalência e a adaptação. Segundo esses autores, quando uma mesma situação é expressa em dois textos com métodos estilísticos e estruturais totalmente distintos, tem-se um caso de equivalência. Derivadas também da proposta de Vinay e Darbelnet são as modalidades de tradução de Francis AUBerT (1998). Elas integram um modelo de pesquisa tradutológica com base em corpus e que visa, principalmente, a análise quantitativa de traduções. Uma revisão dessas modalidades foi proposta por Aubert em 2006, onde ele define que "as modalidades de equivalência são aquelas em que a atuação, interferência e coautoria do tradutor tornam-se mais visíveis" (2006: 65). Em outras palavras, a estratégia da "equivalência" está presente quando o tradutor deixa à mostra a sua preocupação com a receptividade do texto na cultura de chegada.

0 tradutor experiente sabe que uma equivalência "perfeita" entre termos de línguas diferentes não ocorre frequentemente. Para DuBuc (1985: 69) há equivalência "quando o termo na língua de chegada exibe uma identidade completa de sentidos e de usos com o termo da língua de partida, no interior de um mesmo domínio de aplicação". Segundo este autor, essa equivalência perfeita só seria possível se fossem observados três critérios entre os termos: identidade de sentido, de nível sociolinguístico e de uso. $\mathrm{Na}$ maioria dos casos, principalmente em tradução jurídica, encontramos o que Dubuc denomina de equivalência parcial ou correspondência, ou seja, quando "o termo da língua A só recobre parcialmente o campo de significação do termo da língua B e vice-versa" (1985: 69). É o caso dos termos Maire x prefeito, que abordaremos no item 5.

Atualmente, há numerosos estudos linguísticos sobre a tradução jurídica, especialmente no Canadá, desenvolvidos por juristas linguistas como J ean-Claude Gémar, que elaborou em 1979 uma tipologia sobre os problemas da tradução jurídica. Essa primeira obra, bem como a maioria dos artigos que 
Chanut, M. E. P. - A noção de equivalência e a sua especificidade na tradução especializada

escreveu ao longo de sua carreira, foram retomados e publicados em 1995 em uma obra de dois tomos, intitulada Traduire ou l'art d'interpreter. LouisPhilippe Pigéon, autor de La traduction juridique. L'équivalence fonctionnelle (1982), é advogado, juiz e professor na Universidade de Laval (Québec) e considerado um importante teórico canadense, cuja obra foi fundamental neste estudo, pois trata da "equivalência funcional" em tradução jurídica.

Particularmente, o francês Malcolm Harvey, da Universidade Lumière, de Lyon, especialista em tradução jurídica, é autor de um texto intitulado Traduire l'intraduisible, Stratégies d'équivalence dans la traduction juridique (2002), no qual descreve quatro técnicas em tradução jurídica: a equivalência funcional, a equivalência formal, a transcrição, a tradução explicativa.

Harvey afirma que há três tipos de termos cujas diferenças interculturais constituem um perigo para o tradutor jurídico: os conceitos (ex: habeas corpus); as instituições (ex: Tribunal Superior Eleitoral); os atores jurídicos (ex: tabelião, juiz etc.). Nesta pesquisa, nos interessamos particularmente pelos dois últimos, acrescentando-se a esses especialmente os termos usados em documentos civis ou escolares.

O que Dubuc chama de "correspondência", referindo-se aos equivalentes parciais, é tratado por Lerat (1995: 95) como equivalentes funcionais.

Mas, o que se entende por "equivalência funcional'?

\section{A noção de "equivalência funcional"}

A equivalência funcional, tal como a compreendemos atualmente, refere-se ao procedimento pelo qual o tradutor procura, na língua de 
Chanut, M. E. P. - A noção de equivalência e a sua especificidade na tradução especializada

chegada, os elementos linguísticos, contextuais e culturais permitindo-lhe restituir um texto que pode ser funcional na cultura receptora. 0 qualificativo funcional deve ser entendido aqui no sentido pragmático. Quer dizer que 0 objetivo do tradutor é devolver um texto que permite cumprir os mesmos atos, jurídicos ou administrativos, que o texto de partida.

Traduzir, nesse sentido, é um processo que vai além da simples substituição dos elementos lexicais e gramaticais de uma língua por aqueles de outra língua. O êxito da equivalência pode, de fato, compreender "a perda" de elementos linguísticos de base presentes no texto de partida, os quais são substituídos por elementos linguísticos da língua de chegada que tenham uma função equivalente. Isso quer dizer que, nessa busca de uma equivalência funcional, o tradutor se distancia da equivalência linguística, ou seja, aquela que ele obtém traduzindo palavra por palavra.

Traduzir segundo o procedimento da equivalência funcional significa aceitar que a tradução não é uma ciência que comporta termos precisos e unívocos, mas antes, termos aproximativos e desiguais na maior parte do tempo. Os provérbios e as expressões idiomáticas fornecem bons exemplos de equivalência funcional. A equivalência não deve ser procurada nos elementos linguísticos do provérbio e da expressão idiomática, nem na frase em si, nem nas imagens contidas nesta última, mas antes na "função" do provérbio ou da expressão idiomática. 0 provérbio ou a expressão idiomática de partida é substituído por uma expressão na língua de chegada que tenha as mesmas funções na cultura receptora.

Segundo Harvey, há quatro técnicas de tradução utilizadas pelos tradutores na expressão de noções próprias a uma cultura jurídica. Embora a equivalência funcional seja, nesse caso, a estratégia considerada mais adequada, poderemos observar que, na prática, as outras três técnicas de tradução têm sido amplamente utilizadas pelos tradutores jurídicos ou juramentados. 
Chanut, M. E. P. - A noção de equivalência e a sua especificidade na tradução especializada

A equivalência funcional, segundo Harvey (2002), é um procedimento que consiste em encontrar, na língua de chegada, um referente que preencha uma função semelhante. Trata-se de uma adaptação intercultural. Citaríamos como exemplo do francês para o português: Tribunal du commerce como equivalente funcional de "Junta comercial". Harvey afirma que este é o "método ideal de tradução", mas a seguir faz a ressalva de que essa técnica de tradução é satisfatória para "o grande público", mas que deve ser manipulada com precaução em textos jurídicos mais complexos. É por essa razão que os juristas linguistas atualmente valorizam não a identidade da formulação escolhida, mas a identidade dos efeitos jurídicos nas duas versões de um mesmo texto. Ou seja, o importante é a função comunicativa do texto traduzido, como anteriormente descrito por Berman, o que confirma a famosa teoria do Skopos formulada por Vermeer ${ }^{11}$. Enfim, ele observa que a tradução de uma especificidade cultural por outra especificidade cultural também pode obscurecer 0 entendimento.

Em seguida, Harvey analisa a equivalência formal, um procedimento que, como sabemos, é intensamente utilizado na tradução juramentada no Brasil, pois parece "cumprir" melhor a exigência de "fidelidade". Para 0 autor, trata-se de uma equivalência linguística que consiste em traduzir de maneira tão literal quanto possível. Ele cita algumas vantagens desta estratégia, como por exemplo: ela é transparente e sem ambiguidade, permitindo buscar sem dificuldade o termo de origem, embora o texto possa parecer, muitas vezes, "estranho" ao leitor da língua de chegada. Por outro lado, o maior inconveniente é que na tradução literal corre-se um grande risco de se utilizar um falso cognato. Há muitos termos cujos significantes aparentemente "equivalentes" (caso de homônimos, parônimos e outros, cuja

${ }^{11} 0$ termo skopos é de origem grega e significa objetivo ou finalidade. Foi introduzido durante os anos 1970 pelo teórico alemão Hans J. Vermeer para designar o objetivo do texto de chegada e da ação tradutória. Hans J. Vermeer, "Skopos and Commission in Translational Action », editado por Lawrence Venuti, London, Routledge, 2000, p. 223. (Tradução do autor deste artigo do texto em inglês). Aproximou-se aqui a equivalência funcional no sentido de um "obj etivo prático" na cultura receptora da tradução. 
Chanut, M. E. P. - A noção de equivalência e a sua especificidade na tradução especializada

semelhança morfológica é resultante de mera coincidência fonética ou gráfica) são relativamente próximos - às vezes, idênticos - ao passo que seus significados ou usos são distintos. Sem contar que há numerosos falsos cognatos ou locuções semelhantes na expressão significante que fazem, em cada país ou região, referências a realidades ou situações legais e jurídicas distintas. Citaríamos, como exemplo, um falso cognato duplamente perigoso, pois se trata de um termo francês que tem uso particular na Suíça e cuja tradução literal para o português assim como o seu uso inadequado na França passariam despercebidos por um tradutor desavisado. Trata-se do termo syndic (equivalente ao maire na França) que, na Suíça romanda, faz parte de uma terminologia oficial. Na Suíça, não constam as acepções em uso no Brasil e na França para o termo morfologicamente correlato (síndico/syndic), onde esse termo tem acepções idênticas. A definição do termo syndic segundo 0 Dictionnaire suisse-romand é: premier magistrat d'une commune, maire (ThibAult 1997: 681). Mais adiante, trataremos da questão da equivalência envolvendo os termos maire e prefeito.

Harvey cita ainda dois últimos procedimentos que, a nosso ver, são frequentemente utilizados na tradução juramentada, portanto, julgamos interessante mencionar a título de curiosidade. A técnica da transcrição consiste em reproduzir o termo de origem, acrescentando eventualmente uma glosa por ocasião da primeira ocorrência: por exemplo, citaríamos o caso de um documento exigido na Suíça denominado certificat de passage. Não há como identificar a função desse documento se não for explicado ao leitor brasileiro que se trata de um documento escolar atestando a mudança de nível (também denominado bulletin de passage), portanto, o mais adequado, neste caso, seria utilizar a técnica da transcrição do termo original, com 0 acréscimo de glosa. Harvey comenta que essa técnica de tradução é isenta de ambiguidade pelo fato de "não traduzir" e por privilegiar a transparência e a precisão em detrimento da elegância e da concisão. Além disso, permite que se explique detalhadamente na glosa as diferenças significativas entre os 
Chanut, M. E. P. - A noção de equivalência e a sua especificidade na tradução especializada

sistemas das duas culturas. 0 autor ainda comenta que considera a transcrição uma técnica interessante no caso de "manuais de direito", por exemplo. Porém, os tradutores juramentados sabem que este recurso é extremamente indesejável, principalmente em um documento pessoal, cujo formato deveria permanecer o mais próximo possível do original, por questões de funcionalidade e até mesmo de estética. A última técnica descrita por Harvey é a tradução descritiva, que consiste em traduzir as especificidades culturais utilizando termos genéricos, ou seja, evitando longas glosas explicativas, procedimento muito útil no caso dos termos que não possuem equivalentes. Porém, ele critica a técnica descritiva pelo fato de provocar facilmente ambiguidades de interpretação e aconselha que se coloque o termo original entre parênteses. Como exemplo, poderíamos traduzir por "delito" ou "fraude" algum tipo de ação ilegal mais específico cujo termo em francês não tivesse um equivalente em português, mas com o cuidado de deixar o termo original entre parênteses para leituras ou avaliações posteriores.

\section{A equivalência na tradução de documentos civis e escolares}

A prática como tradutora juramentada, assim como os resultados anteriores de pesquisas feitas pelo autor deste artigo e as de outros pesquisadores nesse domínio (BARRos; Aubert; CAMARGO, 2008b, 2008c) mostram que os tipos de documentos mais comumente solicitados à TJ no par de línguas português/ francês são os escolares (diplomas, históricos escolares etc.) e pessoais (certidões de nascimento, casamento, óbito, procurações, carteiras de habilitação etc.), além dos jurídico-societários (estatutos sociais, 
Chanut, M. E. P. - A noção de equivalência e a sua especificidade na tradução especializada

atas de assembleias e outros), e os jurídico-comerciais (contratos de diversos tipos e outros).

Destaca-se a importância que os documentos escolares possuem na sociedade, uma vez que definem e identificam o perfil estudantil e são documentos exigidos no percurso acadêmico e profissional.

Constatou-se no trabalho anterior que um desconhecimento dos sistemas educacionais dos países envolvidos, aliados à tendência literalizante da tradução juramentada, são fatores que podem levar o tradutor a cometer graves erros na transmissão das informações fundamentais presentes em documentos escolares, como por exemplo, nível de estudos, título obtido, formação, curso, disciplinas, notas etc., assim como termos relacionados à redação dos atestados, certificados, diplomas, enfim, toda terminologia da documentação escolar.

Os textos que a Jucesp denomina "comuns" - documentos civis em geral - testemunham como a tradução e a versão juramentada lidam, antes de tudo, com a necessidade de informar, esclarecer e confirmar a legalidade do ato administrativo, notarial ou jurídico. É essa dimensão pragmática que exige do tradutor juramentado uma consciência da importância de se adotar uma estratégia tradutória adequada na busca dos equivalentes. Trata-se de privilegiar a fidelidade linguística ou jurídica? Se o documento oficial a ser traduzido tem validade jurídica, o tradutor deverá levar em conta o sistema jurídico da língua receptora de sua tradução, facilitando a compreensão para que os fins legais sejam perfeitamente atingidos. Ou seja, é a "funcionalidade" e a validade legal do texto que importam.

Os documentos civis, particularmente, devem ser traduzidos de forma documental, ou seja, o objetivo não é uma adaptação ao modelo ou formato do país receptor, mas a apresentação correta e fidedigna dos dados informados. Uma Carteira de Habilitação, por exemplo, deverá servir para que o portador consiga obter um documento similar no país estrangeiro. Não há, 
Chanut, M. E. P. - A noção de equivalência e a sua especificidade na tradução especializada

portanto, necessidade de se imitar as convenções do país de origem, mas apenas as informações essenciais à finalidade de uso da tradução. No caso das certidões de nascimento, ao compararmos os documentos franceses e brasileiros, veremos que eles têm formatos completamente diferentes, porém, uma reprodução fiel do formato original, com todas as informações adequadamente traduzidas, poderá ser útil no caso de um cotejo com 0 documento original. Pode ser questionada por alguma autoridade, a razão pela qual a tradução do documento francês não informa, por exemplo, os nomes dos avôs e avós paternos e maternos, nem das testemunhas. Por outro lado, uma tradução para o francês da certidão brasileira não poderá omitir esses dados, obrigatoriamente presentes no documento brasileiro.

Outra diferença relativa às certidões civis é que, no Brasil, temos apenas um tipo de documento, denominado "certidão", mas na França, existem três tipos de documentos para o mesmo evento, por exemplo: déclaration, acte e extrait de naissance. Na França, a déclaration de naissance é o documento feito imediatamente após o nascimento, no Registro civil do local do nascimento, que se encontra instalado na Mairie ("Prefeitura"); ela é feita geralmente pelo pai e testemunhada pelos médicos responsáveis presentes no parto. 0 acte de naissance é o documento jurídico original definitivo, emitido posteriormente pelo Registro civil e assinado pelo responsável, geralmente o Maire ou seu substituto (par délégation); o extrait de naissance é a "cópia" do documento original (acte), válida no país apenas por três meses, podendo ser emitida uma cópia integral (copie intégrale), com todas as informações e inclusive averbações, ou uma cópia resumida, o extrait, nas versões "com filiação" e "sem filiação". Este último, o extrait de naissance, é o documento francês que geralmente chega às mãos do tradutor juramentado.

Lembrando que, além da problemática da equivalência, outra grande dificuldade está ligada às diferenças entre os dois sistemas administrativos e jurídicos. Os certificados de registro civil são emitidos na França pela 
Chanut, M. E. P. - A noção de equivalência e a sua especificidade na tradução especializada

administração pública (municipal, regional, departamental ou cantonal, no caso da Suíça) enquanto que, no Brasil, eles são expedidos e oficializados por tabelionatos ou cartórios.

De acordo com Rosiléa Pizarro Carnelós ${ }^{12}$

Os cartórios brasileiros, assim como as instituições equivalentes na França, Luxemburgo, Suíça e Itália, por exemplo, representam um marcador cultural extralingüístico (sic) muito importante que pode influenciar o fazer tradutório. A título de exemplo, poderíamos pensar na tradução de "escrevente" em francês e italiano. Essa função existe nos cartórios dos países acima? Iniciemos nossa reflexão por uma distinção: só no Brasil existe o cartório de Registro Civil. Nos outros países em questão, o Registro Civil está vinculado à Prefeitura de cada município, e o responsável pela emissão de documentos do Registro Civil normalmente é o Oficial, o próprio Prefeito ou seu Delegado. (p.27)

Voltando, portanto, à questão da equivalência do termo prefeito, é surpreendente constatar que os dicionários indiquem "prefeito" como o "único" equivalente de maire, uma vez que prefeito é um equivalente de maire apenas parcialmente, ou seja, na função de "chefe do poder executivo nas municipalidades" (Houaiss). Quando este ocupa a função do responsável pelo registro civil e assina as certidões, parece-nos inadequado traduzir maire por "prefeito", então, sugerimos que a assinatura seja identificada pela função de "oficial" que é o "responsável pelo registro civil". No caso das versões das certidões brasileiras para o francês, a tradução das assinaturas dos responsáveis costuma conservar a realidade cartorial brasileira por meio de uma tradução mais formal e menos funcional. 0 "oficial de registro civil" é uma função existente no notariado brasileiro, mas nesses documentos civis outras pessoas também assinam e essas funções variam muito (secretário, oficial maior, oficial interino, escrevente substituto, escrivão, tabelião etc.). Portanto, não há apenas um só responsável e uma só assinatura, como no

\footnotetext{
${ }^{12}$ Tese de Doutorado em Linguística de Rosiléa Pizarro Carnelós - USP - 2005- Disponível em: «ttp:// www.fflch. usp. br/dl/ pos/ teses/ CARNELOSrosilea. pdf >. Acesso em: 30/ 06/ 2010.
} 
Chanut, M. E. P. - A noção de equivalência e a sua especificidade na tradução especializada

documento francês, porém, o dever do tradutor é traduzir todas as informações, nomes e assinaturas, inclusive carimbos pessoais dos assinantes. Fica claro e evidente em uma versão do português para o francês que se trata de realidades completamente diferentes.

A mesma "confusão" ocorre com a figura do préfet na França (no Brasil, um cargo semelhante àquele do nosso Governador estadual, mas cuja função é mais próxima daquela exercida pela Polícia Federal; no caso da França, é o administrador regional). Trata-se de um termo cujo provável correlato em português, pela semelhança morfológica, seria "Prefeito", mas trata-se de um falso cognato, pois como vimos, a função "parcialmente" equivalente do prefeito é exercida pelo Maire ${ }^{13}$.

Para finalizar este artigo, apresenta-se a seguir alguns exemplos de termos franceses que, caso estivessem presentes em um documento oficial, necessitariam de uma tradução mais atenta às especificidades culturais. Exemplos ${ }^{14}$ :

1. canton n. m. " division administrative (inférieure au département) regroupant plusieurs communes » (inclusive, na Suíça e no Canadá, a palavra designa outra coisa)

2. carte grise n. f. « carte de couleur grise tenant lieu de titre de propriété d'un véhicule immatriculé (automobile ou motocyclette), indispensable pour sa mise en circulation »

3. hypokhâgne $n$. f. " première année d'école préparatoire »; khâgne n. f. « deuxième année d'école préparatoire »

4. préfet $n$. m. « haut fonctionnaire nommé par le président de la République par décret pris en Conseil des ministres, et représentant l'État et le gouvernement dans chaque département français »

5. UFR « unité de formation et de recherche (au sein d'une université) 》

${ }^{13}$ Para mais detalhes do estudo específico deste termo, relacionado ao francês da Suíça, conferir o artigo publicado no número 15 da TradTerm (2009).

${ }^{14}$ Exemplos retirados do Dictionnaire suisse romand (1997). 
Chanut, M. E. P. - A noção de equivalência e a sua especificidade na tradução especializada

Alguns termos, por dependerem de estruturas do governo (administração pública, educação pública etc.), são exclusivos de um país e não são empregados em nenhum outro lugar. Os termos apresentados são termos franceses empregados apenas na França. Uma "equivalência funcional" na tradução de tais termos será possível apenas quando a mesma "realidade" existir na língua de chegada, como o caso do maire, mencionado anteriormente, cujo equivalente funcional no caso de documentos pessoais brasileiros é o "oficial de registro civil" e, no caso de documentos suíços, o equivalente é o syndic. No caso anterior, o termo carte grise é o equivalente funcional do documento brasileiro denominado Certificado de Registro de Licenciamento de Veículo (CRLV). Os outros termos apresentados podem ser considerados sem equivalentes na realidade brasileira e, portanto, necessitariam de nota explicativa.

\section{Considerações finais}

O presente trabalho deu ênfase ao método da "equivalência funcional" por se tratar de um procedimento que valoriza o termo na cultura receptora, pois os particularismos das variedades regionais ou nacionais nos provam que até dentro de uma mesma língua um termo pode ter usos administrativos ou jurídicos diferentes.

Em sua perspectiva predominantemente teórica, este estudo buscou investigar se a abordagem funcionalista ou, particularmente, o emprego da "equivalência funcional" constituiria um procedimento mais adequado na tradução juramentada ou jurídica. Esta adequação poderia, assim, liberar o tradutor do conflito relacionado à questão de se traduzir "literalmente" forma/ conteúdo dos termos envolvidos. 0 estudo concluiu, em um primeiro momento, que a questão da literalidade parece ter menos importância na 
Chanut, M. E. P. - A noção de equivalência e a sua especificidade na tradução especializada

medida em que a atenção do tradutor se volta fundamentalmente para um texto de chegada que possa ser "funcional" na cultura receptora. Portanto, o estabelecimento dessa equivalência se situaria, então, em uma espécie de paradoxo: uma vez que a passagem de uma língua para outra é acompanhada pelo resvalamento de uma tradição jurídica para outra, essa "equivalência", que deveria ser "exata", "precisa", "fiel", na realidade só o é aproximativamente.

Em outras palavras, este estudo constata que a exatidão exigida do tradutor jurídico ou juramentada (literalidade, cópia fiel e/ ou exata) depende, paradoxalmente, de conceitos que são relativamente imprecisos pelo fato de estarem prisioneiros da tradição histórica e jurídica na qual se desenvolveram.

Enfim, a proposta de uma reflexão sobre a equivalência funcional na tradução juramentada abordou casos de termos consagrados pelos dicionários bilíngues que consideramos inadequados e os resultados dessa análise foram divulgados na Revista TradTerm n. 15, como já mencionado anteriormente.

Convém assinalar que o presente trabalho restringiu essas abordagens a um questionamento da noção de "equivalência", sem, todavia, ter a pretensão de propor soluções tradutórias definitivas aos termos aqui apresentados.

\section{Referências bibliográficas}

Alpizar-CAstillo, R. Cómo hacer un diccionario cientifico-técnico? La Habana: Félix Varela, 1995.

BarRos, L.A.; AuberT, F.H.; CAmargo, D.C. Tradução juramentada espanholfrancês-português: algumas semelhanças e diferenças terminológicas e de tipologia textual. In: Isquerdo, A.N.; Finatto, M.J.B. (Org.). As Ciências do Léxico: Lexicologia, Lexicografia e Lexicografia. Campo 
Chanut, M. E. P. - A noção de equivalência e a sua especificidade na tradução especializada

Grande: Editora da UFMS/ Programa de Pós-Graduação, 2008b, v. IV, p. $463-481$.

Barros, L. A.; Aubert, F.H.; CAmargo, D.C. Terminologie et typologie textuelle : une contribution à I'étude de la traduction assermentée françaisportugais. In: MANIEZ, F.; DURY, P. (Org.). Lexicographie et terminologie : histoire de mots. Lyon: Presses Universitaires de Lyon, 2008c, p. 347-356.

Base de données lexicographiques panfrancophone (BDLP). Disponível em: বhttp://www.bdlp.org/bdlp.pdf $>$. Acesso em: 21 de julho de 2011.

BASSNETT, S. Translation Studies, London, Routledge, 1991, p. 159.

BERMAN, A. Traduction spécialisée et traduction littéraire. In: La traduction littéraire, scientifique et technique. Actes du colloque International organisé par I'AELPL les 21 et 22 mars 1991. Paris: La Tilv Editeur, p. 9-15.

CATFORD, J.C. A Linguistic Theory of Translation : an essay in applied linguistics. London, Oxford University Press, 1965, p. 103. Reeditado em 2000.

ChANUT, M.E.P. A tradução juramentada de documentos suíços: Resultados parciais em torno dos termos estudados. TradTerm n. 15, São Paulo (FLCH/ USP), 2009, p. 155-171.

Dubuc, R. Manuel pratique de terminologie. Québec: Linguatech Éditeur, 1985.

GalaRnEAU A.; VÉzINA, R. Réfléxions et pratiques relatives à la variation topolectale en terminologie. Québec: Office Québecois de la langue française, 2004, p. 28. Disponível em: «ttp:/ / www. oqlf.gouv. qc.ca/ ressources/ bibliotheque/ officialisation |reflexion topolectale_20080425.pdf>. Acesso em: 20 de julho de 2010.

GEMAR, J.C. La traduction juridique et son enseignement. Meta, vol. 24, n. 1, mar. 1979, p. 35-63.

Gemar, J.C. Traduire ou l'art d'interpréter : langue, droit et société : éléments de jurilinguistique, Tome 2: Application. Québec, Les Presse de I'Université du Québec, 1995b, p. 232.

GentZleR, E. Contemporary Translation Theories, London, Routledge, 1993, p. 224.

HARVEY M. Traduire l'intraduisible, Stratégies d'équivalence dans la traduction juridique, in Le facteur culturel dans la traduction des textes pragmatiques. Ies Cahiers de I'ILCEA, n 3, 2001-2002, p. 39-49. 
Chanut, M. E. P. - A noção de equivalência e a sua especificidade na tradução especializada

Disponível em: বhttp://ilcea. revues. org/index790.html>. Acesso em: 21 de julho de 2010.

Holmes, J. The Name and Nature of Translation Studies - The Translation Studies Reader (ed. Lawrence Venuti). London \& New York: Routledge, 2000, p. 172-185.

J AKOBSON, R. On Linguistic Aspects of Translation. In: The Translation Studies Reader (ed. Lawrence Venuti). London \& New York, Routledge, 2000, p. 113-11.

LeRAT, P. Les langues spécialisées. Paris: PUF, 1995. (Linguistique nouvelle).

Mounin, G. Les problèmes théoriques de la traduction. Paris: Gallimard, 1986, p. 296.

PIGEON, L.P. La traduction juridique. L'équivalence fonctionnelle. In : Langage du droit et traduction. Québec, Éd. J.-C. Gémar, 1982 p. 271-281.

PYM, A. Translation and Text Transfer. New York, Peter Lang, 1992, p. 225.

RODRIGUES, C.C. Tradução e diferença. São Paulo: Editora Unesp, 2000.

SNELL-HORNBY, M. Translation Studies: An Integraded Approch. Amsterdam: J ohn Benjamins, 1988, p. 170. Texto revisado em 1995.

Thibault, A. (Red.) Dictionnaire Suisse Romand: Particularités lexicales du français contemporain. Genève: Éditions Zoé, 1997.

TouRY G. Descriptive Translation Studies and Beyond, Amsterdam, John Benjamins, 1995.

VinaY, J.P.; Darbelnet, J. Stylistique comparée du français et de l'anglais, Montréal, Beauchemin, 1958, 331, p. 8. 